\title{
Iron Retention from Lactoferrin-Supplemented Formulas in Infant Rhesus Monkeys
}

\author{
LAURIE A. DAVIDSON, RICHARD E. LITOV, AND BO LÖNNERDAL
}

Department of Nutrition and California Primate Research Center, University of California, Davis, California 95616 [L.A.D., B.L.] and Mead Johnson Research Center, Bristol-Myers Nutritional Group, Evansville, Indiana 47721 [R.E.L.]

\begin{abstract}
Iron absorption from human milk and infant formula has received much attention, but experimental design problems have been common. In our study, iron retention from human milk, milk-based infant formula (IF) with and without supplemental ferrous sulfate, and IF supplemented with either human or bovine lactoferrin (Lf) was evaluated in infant rhesus monkeys. The exchange of ${ }^{59} \mathrm{Fe}$ (III) $\mathrm{Cl}_{3}$ between the whey, casein, and fat fractions required up to $72 \mathrm{~h}$ to reach the same distribution as intrinsic iron, depending on the type of diet. Infant monkeys were intubated with labeled human milk or IF and counted in a whole body counter. Each infant received all five diets and was also intubated with a reference dose of ${ }^{55} \mathrm{Fe}$ (II) ascorbate. There was no significant difference in iron retention (mean \pm SEM) from the experimental diets: human milk $32.5 \pm 5.1 \%$; IF $32.1 \pm 8.0 \%$; IF + Fe $23.0 \pm 3.9 \%$; IF + human Lf $23.5 \pm 3.3 \%$; IF + bovine Lf $22.7 \pm 4.9 \%$. Therefore, infant monkeys absorb and retain iron similarly from human milk and infant formula. Supplementation of infant formula with human or bovine Lf resulted in similar iron retention to that of ferrous sulfate-supplemented infant formula. (Pediatr Res 27: 176-180, 1990)
\end{abstract}

Abbreviations

IF, infant formula

Lf, lactoferrin

The study of iron absorption from IF has received much attention in recent years. Interest began as a result of the observation that breast-fed infants maintain adequate iron status through 6-9 mo of age, whereas formula-fed infants consuming similar amounts of iron require iron supplementation by about 4 mo $(1,2)$. Siimes et al. (3) found that none of 36 exclusively breast-fed infants exhibited iron deficiency anemia at 9 mo. Iron status of these infants was similar to a control group receiving iron supplemented formula $(6 \mathrm{mg} / \mathrm{L})$. In contrast, low birth wt infants, born with significantly lower iron stores, require iron supplementation at an earlier age. In a study of 15 exclusively breast-fed preterm infants, Iwai et al. (4) found that about $60 \%$ showed signs of iron deficiency at $4 \mathrm{mo}$, and $86 \%$ were iron deficient at $6 \mathrm{mo}$.

A number of studies have attempted to determine the bioavailability of iron from various milks and formulas. These studies conclude that iron absorption from cow milk-based formulas is low, $5-20 \%$, whereas iron uptake from human milk is

Received May, 16, 1989; accepted September 21, 1989.

Correspondence Dr. Bo Lönnerdal, Department of Nutrition, University of California, Davis, CA 95616.

Supported by Bristol-Myers Nutritional Group. considerably higher, $40-70 \%$ (5-14). On closer examination of these studies, however, it can be seen that there are often problems in the experimental design and the values for iron absorption are typically highly variable. In one study, iron absorption in infants fed breast milk ranged from $11-92 \%$ with a mean value of $49 \%$, whereas iron absorption from a homemade cow's milk formula was $1-85 \%$ with a mean value of $20 \%$ (13). Despite the wide variation in iron absorption, this study is frequently cited as evidence that iron absorption from human milk is 2.5 times higher than from cow's milk formula. Because wide variations of this magnitude are common in human studies of iron absorption, administration of each experimental diet to each individual would be an advantage so that each subject could serve as his own control.

Some common problems in experimental design of these studies include the assumption that the extrinsic label added to milk or formula is simulating the absorption of the native, intrinsic iron pool; the use of homemade cow's milk formula, usually diluted cow's milk, which is significantly different in physical characteristics and chemical composition than commercial IF; and the use of experimental models, including human adults and rats, which may not be valid for the human infant.

In an attempt to explain the high bioavailability of human milk iron, Lf has been suggested as a possible enhancer of iron absorption (15). The presence of an intestinal Lf receptor in humans (16) and monkeys (17) has been reported. The receptor may be important in iron absorption by specifically binding dietary Lf and mediating the uptake of iron into the intestinal mucosal cell. However, some investigators have argued that $\mathrm{Lf}$ may inhibit iron absorption due to its high affinity for the mineral (18).

In this study, we have attempted to clarify the issue of iron retention from milk and IF, and in particular, the influence of lactoferrin on iron retention. The suckling rhesus monkey, an excellent model for the human infant, was used along with the radioisotope ${ }^{59} \mathrm{Fe}$ to determine whole body iron retention from a variety of formulas.

\section{MATERIALS AND METHODS}

Animals. Six infant rhesus monkeys being nursed by their mothers and housed at the California Primate Research Center, Davis, CA were used. Infant monkeys were enrolled if they were within the normal limits of iron status for infants as described by Dallman et al. (19). Iron status was also determined at the end of the study. Infants were approximately 1 mo old at the start of the study and they continued to nurse throughout.

Experimental diets. To ensure isotopic equilibration of ${ }^{59} \mathrm{Fe}$ with native milk or formula iron, a preliminary study was performed. ${ }^{59} \mathrm{Fe}(\mathrm{III}) \mathrm{Cl}_{3}(1 \mu \mathrm{Ci})$ (ICN Biomedicals, Inc., Irvine, CA) was added to an aliquot of experimental milk or formula 
and gently stirred at $4^{\circ} \mathrm{C}$. At specified time points $(4,24,48,72$ h) an aliquot was removed, counted in a $\gamma$-well counter (Beckman 8500 , Beckman Instruments, Inc., Fullerton, CA) and ultracentrifuged at $189000 \times \mathrm{g}$ for $1 \mathrm{~h}$ at $4^{\circ} \mathrm{C}$ to separate fat, whey, and casein. Each sample was counted to determine distribution of ${ }^{59} \mathrm{Fe}$ in the various milk fractions. The whey fraction was then applied to a heparin-Sepharose affinity column (Bio-Rad Laboratories, Richmond, CA) equilibrated in $0.05 \mathrm{M}$ Tris- $\mathrm{HCl}(\mathrm{pH}$ 8.0 ), to which Lf binds specifically. The column was eluted with a stepwise sodium chloride gradient; Lf elutes at $0.4-0.5 \mathrm{M} \mathrm{NaCl}$. The $\mathrm{Lf}$ fraction was counted to determine the percentage of ${ }^{59} \mathrm{Fe}$ associated with $\mathrm{Lf}$. Each formula was also analyzed in a single determination for total intrinsic iron content and the distribution of the native iron. Aliquots of the experimental formulas were ultracentrifuged as described above and the fat, whey, and casein fractions separated. Each fraction was wet ashed with concentrated nitric acid and iron quantitated by flame atomic absorption spectrophotometry (Perkin Elmer 3030B, Mountain View, $\mathrm{CA})$.

The experimental diets used were 1) banked pooled human milk (Mother's Milk Bank, San Jose, CA) with a Lf concentration of $1.0 \mathrm{mg} / \mathrm{mL}$ as quantified by rocket immunoelectrophoresis (20); 2) modified Enfamil (IF) (Mead Johnson, Evansville, IN), similar to commercial Enfamil but without added citrate or iron; 3) modified Enfamil plus $12 \mathrm{mg} \mathrm{Fe} / \mathrm{L}$ as ferrous sulfate (IF plus iron); 4) modified Enfamil plus $1 \mathrm{mg} / \mathrm{mL}$ human $\mathrm{Lf}$ ( $25 \%$ iron saturated) (IF plus human Lf), and 5) modified Enfamil plus 1 $\mathrm{mg} / \mathrm{mL}$ bovine $\mathrm{Lf}(25 \%$ iron saturated, New Zealand Milk Products, Inc., Petaluma, CA) (IF plus bovine Lf). Additional details regarding the experimental diets are given in Table 1. The human Lf was isolated from milk collected from healthy lactating donors (21). Modified Enfamil powder was mixed with distilled water to prepare $12.5 \%$ (solids) solutions for the above experimental milk-based IF. Citrate was not added as in commercial IF to eliminate any possible competitive binding for iron between citrate and Lf.

Dosing. On the day of dosing, each infant was removed from its mother and intubated via oral gastric tube with $5 \mathrm{~mL}$ of the experimental diet to help dilute and "wash out" any monkey milk in the stomach. The infants were then fasted for $4 \mathrm{~h}$ to allow for stomach emptying after which they were placed in a small cage to limit movement and counted for $5 \mathrm{~min}$, to determine background radiation, in a whole body $\gamma$-counter equipped with two 4 × 8 " sodium iodide crystals and a ND-66 multichannel analyzer (Nuclear Data, Schaumburg, IL) for signal processing and data output. After whole body counting, the infants were intubated with a meal-sized dose $(10 \mathrm{~mL})$ of experimental diet containing $1 \mu \mathrm{Ci}{ }^{59} \mathrm{Fe}$, added at the appropriate time to allow for equilibration (see Results for details). The infants were immediately counted again to confirm the amount of ${ }^{59} \mathrm{Fe}$ received. After dosing, the monkeys were kept from their mothers for $4 \mathrm{~h}$ to allow for stomach emptying. After $7 \mathrm{~d}$, each monkey was

Table 1. Composition of experimental diets

\begin{tabular}{lccc}
\hline Experimental diet & $\begin{array}{c}\text { Iron } \\
\text { concentration* } \\
(\mathrm{mg} / \mathrm{L})\end{array}$ & $\begin{array}{c}\text { Lactoferrin } \\
\text { concentration } \dagger \\
(\mathrm{mg} / \mathrm{mL})\end{array}$ & $\begin{array}{c}\text { Equilibration } \\
\text { with }{ }^{59} \text { Feł } \\
(\mathrm{h})\end{array}$ \\
\hline HM & 0.53 & 1.0 & 72 \\
IF & 0.11 & & 72 \\
IF plus iron & 11.4 & & 72 \\
IF plus human Lf & 0.46 & 1.0 & 48 \\
IF plus bovine Lf & 0.46 & 1.0 & 48 \\
\hline
\end{tabular}

* Iron content as determined by atomic absorption spectrophotometry (see "Materials and Methods").

$\dagger$ Lactoferrin concentration as determined by rocket immunoelectrophoresis.

Equilibration time determined by distribution study ("Materials and Methods"). counted again to determine whole body iron retention, followed by administration of the second experimental diet. The cycle was repeated for a total of four intubations. The 7-d interval was chosen after determining all unabsorbed ${ }^{59} \mathrm{Fe}$ had been excreted by this time. The retention values were corrected for ${ }^{59} \mathrm{Fe}$ isotopic decay and for biologic loss, assuming a $1 \%$ loss of iron per day.

Reference dose. To determine the variation in iron retention capacity between subjects, each monkey was given an oral reference dose of ferrous sulfate (22). Approximately $1 \mathrm{wk}$ before administration of the first ${ }^{59} \mathrm{Fe}$-labeled diet, each subject was intubated with $1 \mu \mathrm{Ci}^{55} \mathrm{Fe}$ (III) $\mathrm{Cl}_{3}$ in $5 \mathrm{~mL} 0.01 \mathrm{M} \mathrm{HCl}$ containing $30 \mathrm{mg}$ ascorbic acid and $3 \mathrm{mg}$ ferrous sulfate. One wk later, a 1$\mathrm{mL}$ blood sample was drawn and ${ }^{55} \mathrm{Fe}$ quantified after digestion and decolorization of the blood as follows (23). An aliquot of whole blood $(0.3 \mathrm{~mL})$ was digested with $1.0 \mathrm{~mL}$ of Protosol:95\% ethanol $(1: 2, \mathrm{vol} / \mathrm{vol})$ (New England Nuclear, Boston, MA) in a shaking water bath at $60^{\circ} \mathrm{C}$ for $1 \mathrm{~h}$. After cooling to room temperature, $0.5 \mathrm{~mL}$ of $30 \%$ hydrogen peroxide was added and the samples heated in the $60^{\circ} \mathrm{C}$ shaking water bath for $30 \mathrm{~min}$. After cooling, $15 \mathrm{~mL}$ Ready gel (Beckman) was added and the samples were shaken vigorously followed by neutralization with $0.5 \mathrm{~mL}$ of $0.5 \mathrm{~N} \mathrm{HCl}$. The samples, which retained a slight yellow tinge, were counted using a Beckman LS 3801 scintillation counter with an efficiency of approximately $20 \%$. Iron retention was estimated assuming $80 \%$ incorporation of iron into red blood cells and correcting for isotopic and biologic decay.

Meal size. To determine if there is any effect of meal size on iron retention, a pilot study was performed. Five weaned infant rhesus monkeys (5-6 mo) with adequate iron status were intubated as described above with 1 or $20 \mathrm{~mL}$ of the milk-based IF with or without $1 \mathrm{mg} / \mathrm{mL}$ human $\mathrm{Lf}$ ( $25 \%$ iron saturated), containing $1 \mu \mathrm{Ci}{ }^{59} \mathrm{Fe}$. The total amount of iron was adjusted to be the same in the 1 - and $20-\mathrm{mL}$ meal size dose of the two IF, $9.2 \mu \mathrm{g} \mathrm{Fe}$. Ferrous sulfate was added to make up the differences between the four meal size doses. Whole body counting was performed as described above. Each monkey went through four cycles, receiving each of the four experimental diets one time.

Data analysis. Comparisons between treatments were made using analysis of variation for a cross-over design. Comparisons between treatments were evaluated by Duncan's multiple range test. Results were considered significantly different when the probability of the test statistics was less than or equal to 0.05 .

\section{RESULTS}

${ }^{59} \mathrm{Fe}$ added to the milk and formulas required up to $72 \mathrm{~h}$ to reach a similar distribution between the whey, casein, and fat fractions as the intrinsic iron (Table 2). After $48 \mathrm{~h}$, the ${ }^{59} \mathrm{Fe}$ added to milk-based IF plus human Lf had a similar distribution as the intrinsic iron. However, in the human milk or IF with no added iron, the ${ }^{59} \mathrm{Fe}$ required $72 \mathrm{~h}$ before reaching a distribution similar to the native iron.

Monkeys used in these studies had adequate iron status as determined by $\mathrm{Hb}$, hematocrit, serum ferritin, mean corpuscular volume, and transferrin saturation. The individual and mean values for the monkeys at the beginning and end of the study are shown in Table 3 . The retention of ${ }^{55} \mathrm{Fe}$ from the reference dose of ferrous ascorbate ranged from $21-79 \%$ with a mean \pm SEM of $41 \pm 6.9 \%$.

A significant effect of meal size on iron retention was found in the pilot study (Fig. 1). The 1-mL meal size compared to the $20-\mathrm{mL}$ meal size led to a greater percentage of iron retained from both diets tested. The IF with no iron resulted in a mean iron retention of $46 \%$ from $1 \mathrm{~mL}$ as compared to $11 \%$ from the 20 mL meal size dose. The differences in iron retention due to meal size was less pronounced with the IF with human Lf, the 1- and 20 -mL meal sizes resulted in iron retentions of 28 and $17 \%$, respectively.

Iron retention by the infant monkeys fed $10-\mathrm{mL}$ samples of the five experimental diets are shown in Figure 2. Mean $( \pm$ SEM) 
Table 2. Distribution of intrinsic iron and added ${ }^{59} \mathrm{Fe}(I I I) \mathrm{Cl}_{3}$ in test diets*

\begin{tabular}{|c|c|c|c|c|c|}
\hline & & Whey† & Casein & Fat & Lactoferrin \\
\hline \multirow[t]{5}{*}{ Human milk } & Intrinsic iron & $62 \%$ & 17 & 21 & (14) \\
\hline & $4 \mathrm{~h}$ & 81 & 6 & 13 & (11) \\
\hline & $24 \mathrm{~h}$ & 81 & 7 & 12 & (15) \\
\hline & $48 \mathrm{~h}$ & 77 & 9 & 14 & (22) \\
\hline & $72 \mathrm{~h}$ & 64 & 15 & 22 & (17) \\
\hline \multirow[t]{5}{*}{ Milk-based infant formula } & Intrinsic iron & 32 & 40 & 27 & \\
\hline & $4 \mathrm{~h}$ & 65 & 14 & 20 & \\
\hline & $24 \mathrm{~h}$ & 56 & 19 & 25 & \\
\hline & $48 \mathrm{~h}$ & 50 & 25 & 25 & \\
\hline & $72 \mathrm{~h}$ & 29 & 39 & 32 & \\
\hline \multirow{5}{*}{$\begin{array}{l}\text { Milk-based infant formula plus hu- } \\
\text { man Lf }\end{array}$} & Intrinsic iron & 59 & 17 & 24 & $(51)$ \\
\hline & $4 \mathrm{~h}$ & 65 & 13 & 22 & (47) \\
\hline & $24 \mathrm{~h}$ & 69 & 12 & 19 & $(56)$ \\
\hline & $48 \mathrm{~h}$ & 60 & 12 & 28 & (46) \\
\hline & $72 \mathrm{~h}$ & 48 & 11 & 41 & $(25)$ \\
\hline \multirow{5}{*}{$\begin{array}{l}\text { Milk-based infant formula plus bo- } \\
\text { vine Lf }\end{array}$} & Intrinsic iron & 32 & 32 & 36 & $(21)$ \\
\hline & $4 \mathrm{~h}$ & 39 & 25 & 37 & (19) \\
\hline & $24 \mathrm{~h}$ & 41 & 22 & 36 & (27) \\
\hline & $48 \mathrm{~h}$ & 41 & 26 & 33 & (24) \\
\hline & $72 \mathrm{~h}$ & 40 & 24 & 36 & (20) \\
\hline
\end{tabular}

* The values in each time period row $\left(4-72 \mathrm{~h}\right.$ ) are the percent of added ${ }^{59} \mathrm{Fe}$ found in each of the various diet fractions.

$\dagger$ The percent of the iron associated with the whey fraction includes Lf as well as all other whey components. The percent iron associated with lactoferrin alone is given in the fourth column.

Table 3. Initial and final iron status of the suckling rhesus monkeys

\begin{tabular}{|c|c|c|c|c|c|c|c|c|c|}
\hline & Infant & $\begin{array}{l}\text { Age } \\
\text { (d) }\end{array}$ & $\begin{array}{l}\mathrm{Wt} \\
(\mathrm{g})\end{array}$ & $\begin{array}{c}\mathrm{Hb} \\
(\mathrm{g} / \mathrm{L})\end{array}$ & $\begin{array}{c}\text { Hematocrit } \\
(\%)\end{array}$ & $\begin{array}{l}\text { Serum } \\
\text { ferritin } \\
(\mu \mathrm{g} / \mathrm{L})\end{array}$ & $\begin{array}{l}\text { Mean } \\
\text { corpuscular } \\
\text { volume } \\
\text { (fl) }\end{array}$ & $\begin{array}{c}\text { Transferrin } \\
\text { saturation } \\
(\%)\end{array}$ & $\begin{array}{c}{ }^{55} \mathrm{Fe} \text { retention } \\
\text { from } \\
\text { reference } \\
\text { dose } \\
(\%)\end{array}$ \\
\hline \multirow[t]{7}{*}{ Initial } & 1 & 47 & 624 & 114 & 0.34 & 16.2 & 71.6 & 0.40 & 78.8 \\
\hline & 2 & 45 & 501 & 127 & 0.39 & 74.3 & 79.2 & 0.31 & 26.6 \\
\hline & 3 & 42 & 610 & 146 & 0.45 & 21.1 & 80.3 & 0.33 & 60.6 \\
\hline & 4 & 41 & 620 & 114 & 0.35 & 26.0 & 81.5 & 0.36 & 33.9 \\
\hline & 5 & 34 & 490 & 140 & 0.36 & 24.2 & 83.4 & 0.46 & 27.5 \\
\hline & 6 & 26 & 459 & 171 & 0.51 & 20.6 & 89.8 & 0.58 & 21.2 \\
\hline & Mean & 39 & 551 & 135 & 0.40 & 30.4 & 81.0 & 0.40 & 41.4 \\
\hline \multirow[t]{7}{*}{ Final } & 1 & 82 & 781 & 115 & 0.37 & 12.0 & 76.7 & 0.16 & \\
\hline & 2 & 80 & 550 & 111 & 0.32 & 20.2 & 71.4 & 0.18 & \\
\hline & 3 & 77 & 769 & 136 & 0.41 & 13.1 & 89.0 & 0.48 & \\
\hline & 4 & 76 & 775 & 117 & 0.35 & 28.9 & 72.6 & 0.23 & \\
\hline & 5 & 69 & 618 & 131 & 0.37 & 13.8 & 74.0 & 0.37 & \\
\hline & 6 & 61 & 564 & 120 & 0.36 & 18.9 & 73.1 & 0.48 & \\
\hline & Mean & 74 & 676 & 122 & 0.36 & 17.8 & 76.1 & 0.32 & \\
\hline \multicolumn{4}{|c|}{ Indication of iron deficiency* } & $<110$ & $<0.32$ & $<10.0$ & $<70.0$ & $<0.10$ & \\
\hline
\end{tabular}

${ }^{*}$ From Dallman et al. (19).

iron retention from human milk was $32.5 \pm 5.1 \%$; IF without added iron, $32.1 \pm 8.0 \%$; IF supplemented with $12 \mathrm{mg}$ ferrous sulfate/L, $23.0 \pm 3.9 \%$; IF with $1 \mathrm{mg}$ human $\mathrm{Lf} / \mathrm{mL}, 23.5 \pm$ $3.3 \%$; and IF with $1 \mathrm{mg}$ bovine $\mathrm{Lf} / \mathrm{mL}, 22.7 \pm 4.9 \%$. There was no statistically significant difference $(p>0.05)$ in iron retention between any of the experimental diets or over time.

\section{DISCUSSION}

A number of factors may contribute to the low values for iron absorption from cow's milk and formulas reported in earlier studies. Some reports describe the formula used as a homemade cow's milk-based formula (11-13). This may simply be regarded as cow's milk diluted with water. Commercial IF are processed and have a chemical composition (whey:casein ratio, minerals, vitamins, and fats) different from that of cow's milk. Thus, iron bioavailability measurements of homemade formulas may not be representative of currently available commercial IF. The bioavailability of iron from milk-based IF may be higher than from cow's milk because they are higher in ascorbic acid and lower in calcium compared to cow's milk and homemade formulas. It has been shown that addition of ascorbic acid to cow's milk formula significantly increases iron absorption (24) and that a high level of calcium can inhibit iron absorption (25). A study of iron absorption in human infants by Rios et al. (10) showed 


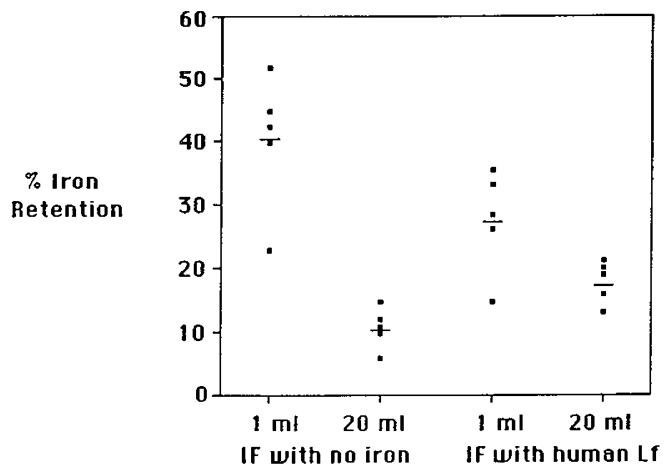

Fig. 1. Iron retention in weaned (5-6 mo old) rhesus monkeys. Infants were intubated with either 1 or $20 \mathrm{~mL}$ milk-based IF with or without $1 \mathrm{mg}$ human $\mathrm{Lf} / \mathrm{mL} .{ }^{59} \mathrm{Fe}$ retention was determined after $1 \mathrm{wk}$ by whole body counting. Values from each monkey are given, with the bar indicating the mean.

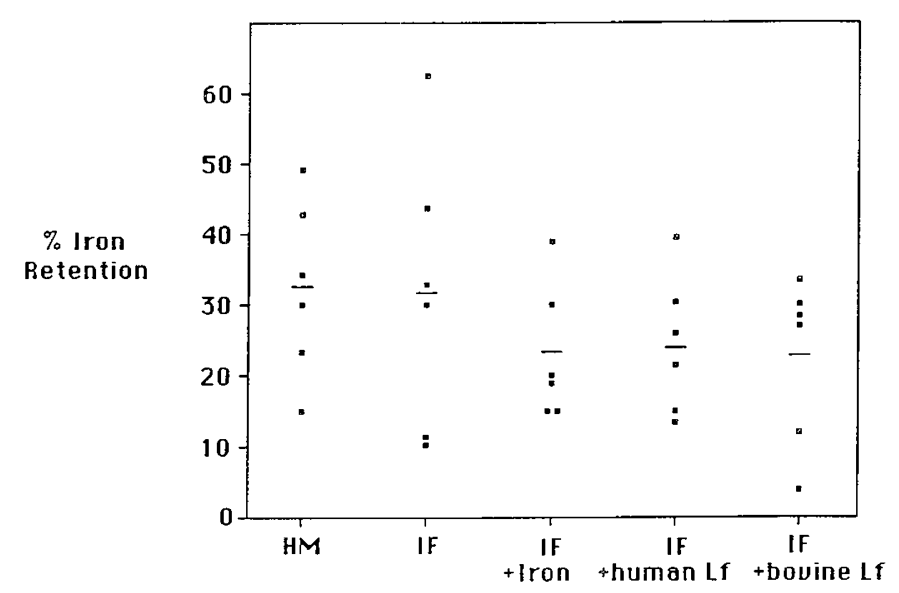

Experimental Diet

Fig. 2. Iron retention in suckling rhesus monkeys. Infants were intubated with $10 \mathrm{~mL}$ human milk or milk-based IF with or without ferrous sulfate or Lf. ${ }^{59} \mathrm{Fe}$ retention was determined after 1 wk by whole body counting. Values from each monkey are given, with the bar indicating the mean.

low iron absorption from IF. However, this study may have suffered from methodologic problems as the absorption of iron from the reference dose was as low as $6-8 \%$. Comparing the results of this study to data reported in the literature, the bioavailability of iron from commercial cow's milk-based IF is typically higher than from cow's milk or homemade cow's milk formulas.

A factor that may influence iron retention, is the method of labeling the milk or formula with the radioisotope. We observed a significant redistribution of ${ }^{59} \mathrm{Fe}$ depending on the type of diet. $\mathrm{Up}$ to $72 \mathrm{~h}$ was required for the isotope to distribute among the different fractions similarly to the intrinsic iron. However, many studies of iron absorption have been performed by adding the isotope immediately before feeding or in some cases by administering the ${ }^{59} \mathrm{Fe}$ as a separate solution during the feeding of the formula $(11,13,14)$. The assumption has been that the native and isotopic iron enter a common pool in the intestine. This may not be the case for formulas and milk, which contain various binding ligands such as citrate, casein, and Lf.

Another important factor that can affect iron retention is meal size. When weaned rhesus monkeys were given $1-\mathrm{mL}$ doses of IF with or without human Lf, iron retention was significantly higher $(p \leq 0.05)$ than when 20 -mL meal size doses were given.
A meal size of $20 \mathrm{~mL}$ IF with no iron resulted in a considerable decrease in iron retention from 46 to $11 \%$. A meal size of $20 \mathrm{~mL}$ IF with human Lf resulted in a smaller decrease in iron retention from 28 to $17 \%$. There were no significant differences in iron retention between IF with or without human Lf when the meal size was the same at 1 or $20 \mathrm{~mL}$. The greater amount of proteolytic enzymes and gastric acid in the gastrointestinal tract relative to a $1-\mathrm{mL}$ meal compared to a $20-\mathrm{mL}$ meal of formula, may result in more extensive digestion and solubilization of the iron from the 1-mL sized meal. This would lead to a greater absorption of iron from the $1-\mathrm{mL}$ dose compared to the $20-\mathrm{mL}$ dose.

Suckling infant monkeys have a smaller stomach capacity than weaned infants and do not tolerate a $20-\mathrm{mL}$ bolus. A meal size of $10 \mathrm{~mL}$ was chosen for determining iron retention from the five diets in the suckling rhesus monkeys. These infants retained a significant proportion of the iron from all experimental formulas. Iron requirements are high in early infancy due to rapid growth and increase in blood volume. It is possible that these infants absorbed and retained a high percentage of iron from all the formulas because of high iron demands. In addition, the experimental design used here did not allow for adaptation to the experimental diets. All monkeys were maintained on monkey milk for the duration of the experiment and given each diet on only one occasion. This eliminates the down-regulation that would likely occur if the infant was fed for a longer period with a high iron diet. Thus, the inherant iron bioavailability from each diet was assessed with no allowance for intestinal or systemic adaptation by the infant.

A recent study by Fairweather-Tait et al. (26) compared iron absorption from a commercial cow's milk-based formula containing either ferric chloride plus ascorbate, or bovine Lf as the iron source. Iron retention in 7-d-old human infants was not significantly different between the two groups. The $\mathrm{FeCl}_{3}$ plus ascorbate group averaged $44.4 \%$ and the bovine Lf group averaged $46.2 \%$ iron retention. Our data are in agreement with this study, showing that newborn infants retain a large and similar percentage of iron presented either with $\mathrm{Lf}$ or as an inorganic salt added to a milk-based formula. We have previously reported the presence of an intestinal Lf receptor in the rhesus monkey (17). The receptor may participate in iron absorption by specifically binding dietary lactoferrin and mediating the uptake of iron into the intestinal cell. For this to occur, Lf must remain structurally intact during gastrointestinal digestion. Previously, we have shown that a percentage of ingested Lf does survive digestion and passes intact into the feces of breast-fed human infants (27). Apparently in this study, the iron from Lf is either released from Lf during digestion and absorbed as inorganic iron or if the Lf binds to the intestinal receptor and releases the iron, the uptake is similar to that of inorganic iron.

The choice of subjects and the experimental model is critical in determining iron bioavailability from IF. Iron absorption decreases with age (28), probably due to maturational changes in intestinal transport mechanisms. This most likely explains why several studies on older infants $(11,14)$ indicate lower absorption values from unfortified formula than our study and that of Fairweather-Tait et al. (26). Numerous iron bioavailability studies have been done with human adults. However, there are significant physiologic differences between human adults and infants. The digestive capacity of adults has been shown to be greater than in infants. First, the secretion of trypsin, chymotrypsin, and a number of other pancreatic enzymes is considerably lower in the infant than the adult (29). More extensive digestion of a meal may free a greater amount of iron for absorption. Second, the rapid growth and increasing blood volume of an infant results in a greater demand for iron by an infant than by an adult. With regard to other species, the rat has served as a model in many studies of iron bioavailability. However, caution must be exercised in the interpretation of these results, because the mechanisms of iron absorption in the rat are different than 
in the human. For example, non-heme iron is more bioavailable than heme iron in the rat; the reverse is true for humans (30).

Since obtaining institutional review board approval for the use of radioisotopes in human infants is difficult, the suckling rhesus monkey provides the next best model to study iron bioavailability that is applicable to human infants. The mean iron retention of $41 \%$ in the infant monkeys from the ${ }^{55} \mathrm{FeCl}_{3}$ reference dose indicates the similarity to humans, where absorption from an iron reference dose has been found to average $40 \%$ (31). The gastrointestinal function in the infant monkey and the human neonate are similar with regard to stomach $\mathrm{pH}$ and proteolytic digestion of milk proteins (32). Lf from rhesus milk has been demonstrated to be similar to human $\operatorname{Lf}(21)$. The proteins share similar mol wt, amino acid composition, N-terminal amino acid sequence, and glycan structures. The concentration of $\mathrm{Lf}$ in rhesus and human milk is similar and much higher than in milk from most other species (33). In addition, both human and rhesus Lf cross-react with the human Lf antibody; whereas, Lf from the many other species tested do not.

In conclusion, the suckling infant monkey absorbs and retains iron similarly from human milk and IF, with means ranging from 23 to $32 \%$. Human or bovine Lf added to IF resulted in similar whole body iron retention as ferrous sulfate-supplemented IF. Formulas administered as a larger meal size $(20 \mathrm{~mL})$ resulted in significantly less iron retained than with a smaller meal size $(1 \mathrm{~mL})$.

Acknowledgment. The authors thank Carol Brown and the Colony Services staff of the California Primate Research Center and John Schwind of the Laboratory for Energy-Related Health Research for excellent technical support.

\section{REFERENCES}

1. Saarinen UM 1978 Need for iron supplementation in infants on prolonged breast feeding. J Pediatr 93:177-180

2. Duncan B, Schifman RB, Corrigan JJ, Schaefer C 1985 Iron and the exclusively breast-fed infant from birth to 6 months. J Pediatr Gastroenterol Nutr $4: 421-425$

3. Siimes MA, Salmenpera L, Perheentupa J 1984 Exclusive breast-feeding for 9 months: risk of iron deficiency. J Pediatr 104:196-199

4. Iwai Y, Nakao Y, Mikawa H 1986 Iron status in low birth weight infants on breast and formula feeding. Eur J Pediatr 145:63-65

5. Garry PJ, Owen GM, Hooper EM, Gilbert BA 1981 Iron absorption from human milk and formula with and without iron supplementation. Pediatr Res 15:822-826

6. Heinrich HC, Gabbe EE, Whang DH, Bender-Gotze C, Schafer K 1975 Ferrous and hemoglobin- ${ }^{59} \mathrm{Fe}$ absorption from supplemented cow's milk in infants with normal and depleted iron stores. Z. Kinderheilk 120:251-258

7. McMillan J, Landaw S, Oski F 1976 Iron sufficiency in breast-fed infants and the availability of iron from human milk. Pediatrics 58:686-691

8. McMillan JA, Oski FA, Lourie G, Tomarelli RM, Landaw SA 1977 Iron absorption from human milk, simulated human milk, and proprietary formulas. Pediatrics $60: 896-900$

9. Oski FA, Landaw SA 1980 Inhibition of iron absorption from human milk by baby food. Am J Dis Child 134:459-460

10. Rios E, Hunter RE, Cook JD, Smith NJ, Finch CA 1975 The absorption of iron as supplements in infant cereal and infant formulas. Pediatrics 55:686693

11. Saarinen UM, Siimes MA 1977 Iron absorption from infant milk formula and the optimal level of iron supplementation. Acta Paediatr Scand 66:719-722

12. Saarinen U, Siimes MA 1979 Iron absorption from breast milk, cow's milk, and iron supplemented formula: an opportunistic use of changes in total body iron determined by hemoglobin, ferritin, and body weight in 132 infants. Pediatr Res 13:143-147

13. Saarinen U, Siimes M, Dallman P 1977 Iron absorption in infants: high bioavailability of breast milk iron as indicated by the extrinsic tag method of iron absorption and by the concentration of serum ferritin. J Pediatr 91:36-39

14. Stekel A, Olivares M, Pizarro F, Chadud P, Lopez I, Amar M 1986 Absorption of fortification iron from milk formulas in infants. Am $\mathbf{J}$ Clin Nutr 43:917922

15. Lönnerdal B 1984 Iron in breast milk. In: Stekel A (ed) Iron Nutrition in Infancy and Childhood, Vol 4. Nestle Nutrition Workshop Series, Vevey/ Raven Press, New York, pp 95-118

16. Cox TM, Mazurier J, Spik G, Montreuil J, Peters T 1979 Iron binding protein and influx of iron across the duodenal brush border. Evidence for specific lactoferrin receptors in the human intestine. Biochim Biophys Acta 588:120128

17. Davidson LA, Lönnerda1 B 1988 Specific binding of lactoferrin to the brush border membrane: ontogeny and effect of glycan chain. Am J Physiol 254:G580-G585

18. deVet BJCM, vanGool J 1974 Lactoferrin and iron absorption in the small intestine. Acta Med Scand 196:393-402

19. Dallman PR, Siimes MA, Stekel A 1980 Iron deficiency in infancy and childhood. Am J Clin Nutr 33:86-118

20. Laurell C-B 1966 Quantitative estimation of proteins by electrophoresis in agarose gel containing antibodies. Anal Biochem 15:45-52

21. Davidson LA, Lönnerdal B 1986 Isolation and characterization of Rhesus monkey milk lactoferrin. Pediatr Res 20:197-201

22. Layrisse M, Cook JD, Martinez-Torres C, Roche M, Kuhn IN, Finch CA 1969 Food iron absorption: a comparison of vegetable and animal foods. Blood $33: 430-443$

23. Kobayashi Y, Harris WG 1983 Preparation of whole blood for liquid scintillation counting. New England Nuclear Liquid Scintillation Counting Application Notes \#1-30, p 2, NEN/Dupont Co., Wilmington, DE

24. Gillooly M, Torrance JD, Bothwell TN, MacPhail AP, Derman DM, Mills W, Mayet F 1984 The relative effect of ascorbic acid on iron absorption from soy-based and milk-based infant formulas. Am J Clin Nutr 40:522-527

25. Barton JC, Conrad NE, Parmley RT 1983 Calcium inhibition of inorganic iron absorption in rats. Gastroenterology 84:90-101

26. Fairweather-Tait SJ, Balmer SE, Scott PH, Ninski MJ 1987 Lactoferrin and iron absorption in newborn infants. Pediatr Res 22:65l-654

27. Davidson LA, Lonnerdal B 1987 Persistence of human milk proteins in the breast-fed infant. Acta Paediatr Scand 76:733-740

28. Garby L, Sjolin S 1959 Absorption of labelled iron in infants less than three months old. Acta Paediatrica 48(suppl 117): 24-28

29. Lebenthal E, Lee PC, Heitlinger LA 1983 Impact of development of the gastrointestinal tract on infant feeding. J Pediatr 102:1-9

30. Bannerman RM 1965 Quantitative aspects of hemoglobin-iron absorption. J Lab Clin Med 65:944-950

31. Magnusson B, Björn-Rasmussen E, Hallberg L, Rossander L 1981 Iron absorption in relation to iron status. Model proposed to express results of food iron absorption measurements. Scand J Haematol 27:201-208

32. Llanes TE, Lönnerdal B, Cox KL, Anderson J, Cheung ATW 1987 In vivo digestibility of human milk and infant formulas. Am J Clin Nutr 45:836(abstr)

33. Masson P, Heremans J 1971 Lactoferrin in milk from different species. Comp Biochem Physiol B39:119-129 